\title{
Ciudad, Educación y Escuela
}

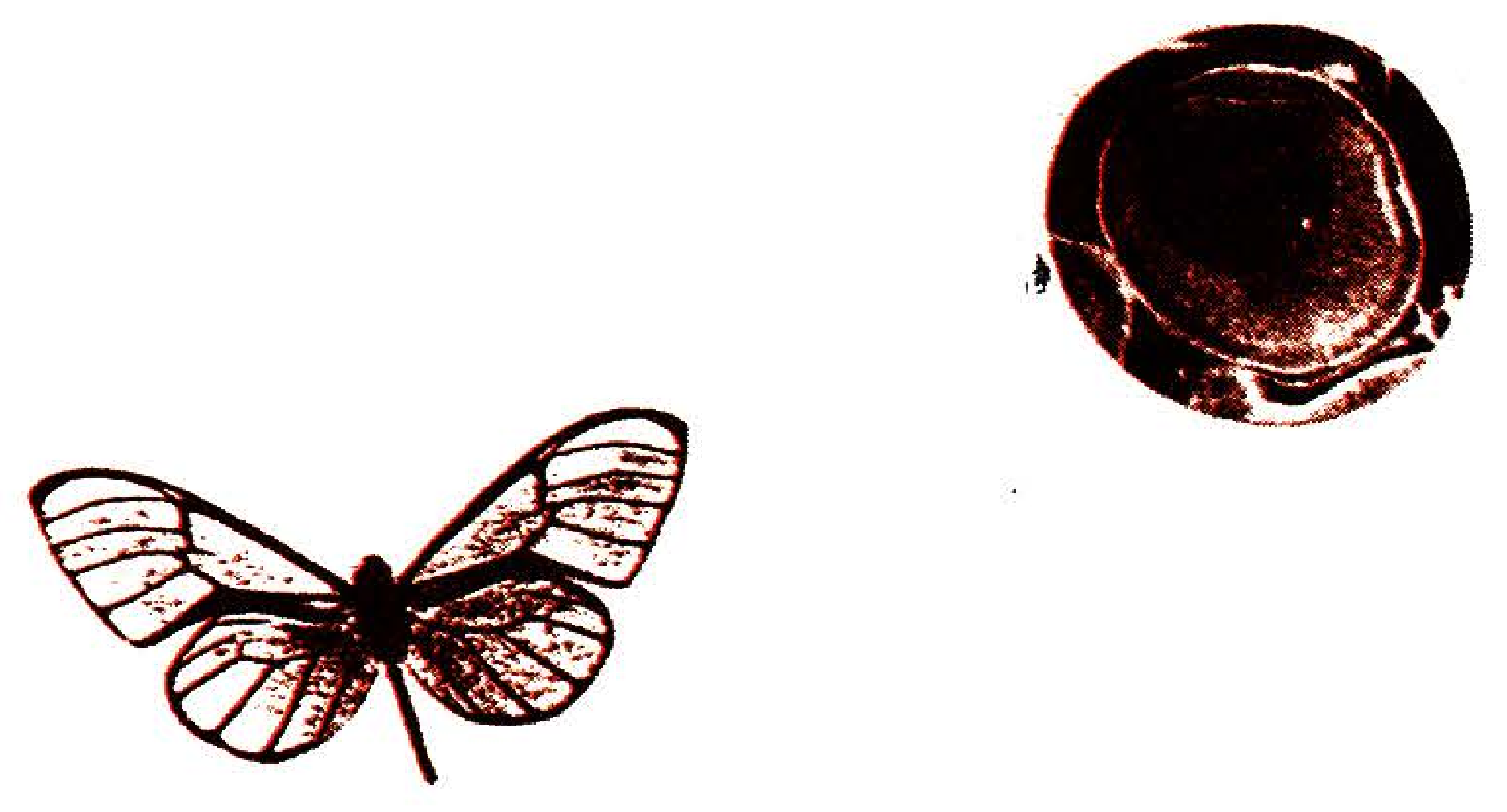

40

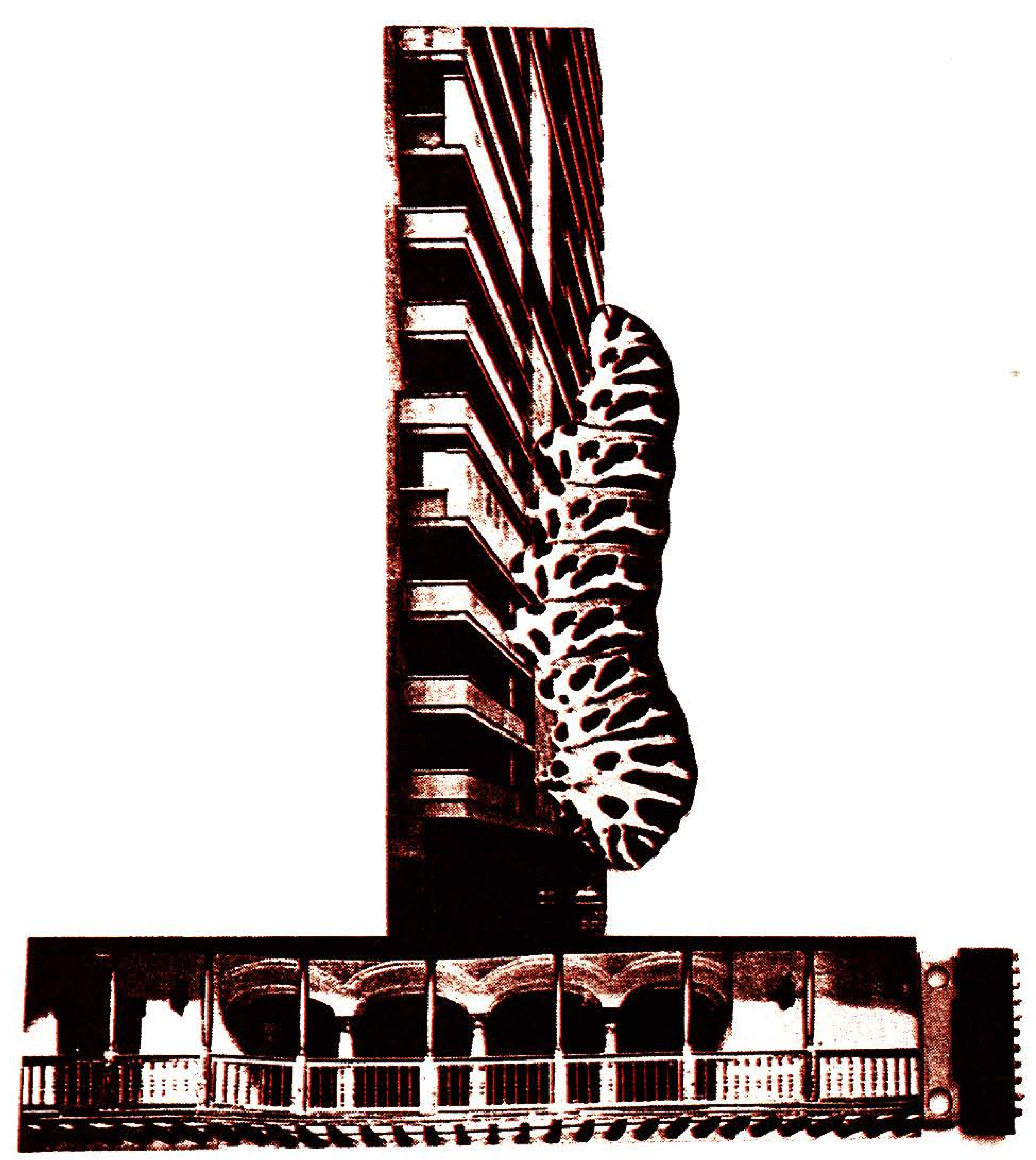

*Profesor Universidad Pedagógica Nacional, Miembro de la Sociedad Colombiana de Pedagogía

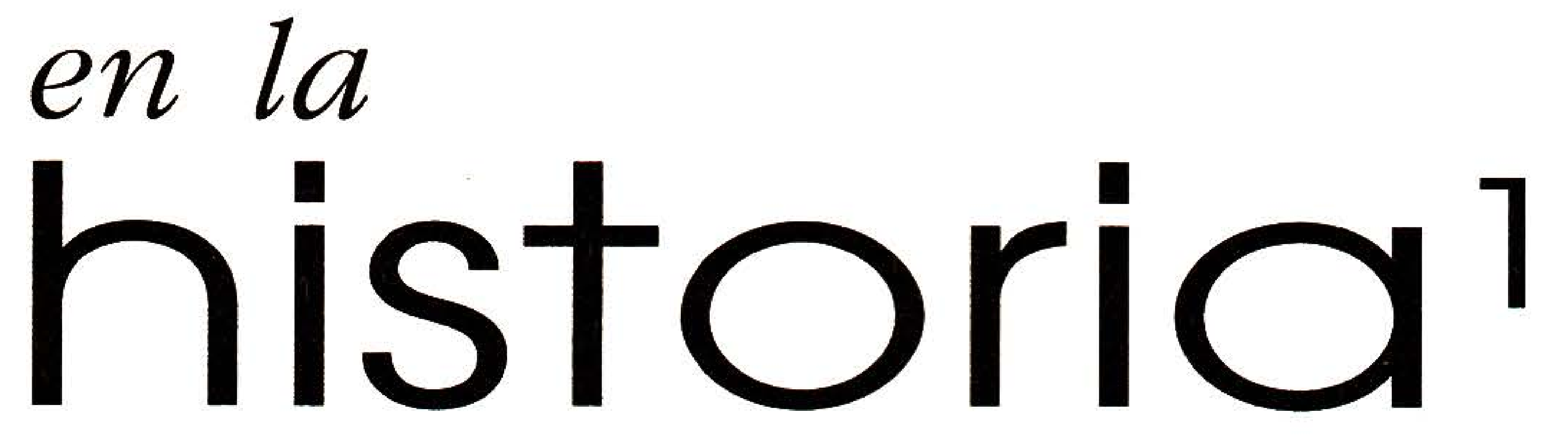

Alejandro Alvarez Gallego*

\section{Presentación}

Para muchos historiadores la escuela es un acontecimiento fundamentalmente urbano ${ }^{2}$. Pero ¿qué escuela, para qué ciudad, fue la que originalmente surgió? No sería difícil ponernos de acuer-

1. Este artículo recoge algunos avances de la investigación: Ciudad, Educación y Escuela. Un estudio comparado de Bogotá y Medellín, 1930-1970, financiada por el IDEP. Participan en ella, además del autor, Carlos Ernesto Noguera, Jorge Orlando Castro y María Solita Quijano.

2. Jacques Le Goff, por ejemplo, en Los intelectuales en la Edad Media, plantea: "La división del trabajo, la ciudad, nuevas instituciones, un espacio cultural común a toda la cristiandad y no ya encarnado en el parcelamiento geográfico y político de la Alta Edad Media son los rasgos esenciales del nuevo paisaje intelectual de la cristiandad occidental en el paso del siglo XII al siglo XIII. Lo que en efecto es decisivo en el modelo intelectual medieval es su vínculo con la ciudad. La revolución escolar se inscribe en la revolución urbana de los siglos que van del X al XIII". 


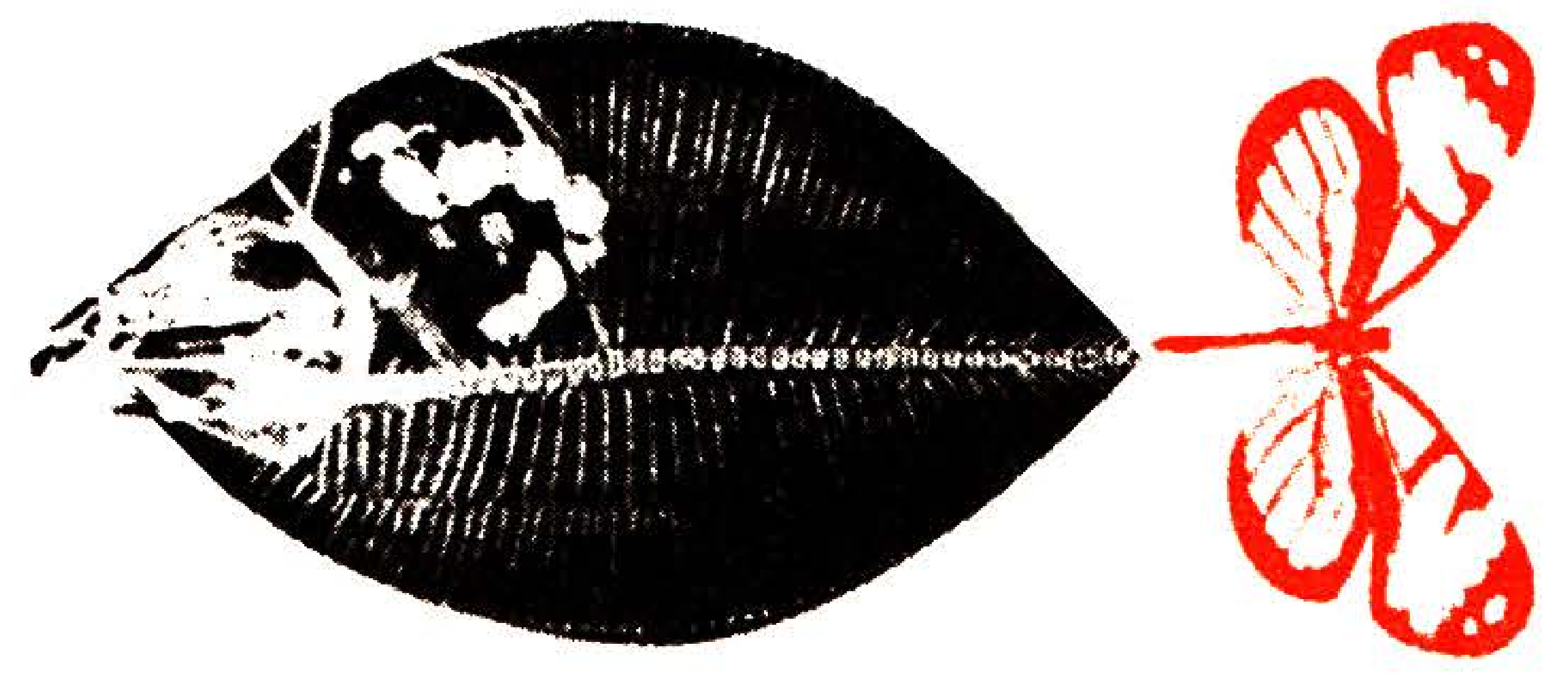

do en aceptar que la escuela cambia con el tiempo, lo cual implica aceptar su condición temporal, pero ¿qué le ha pasado en relación con el espacio urbano en el cuál surgió?, o dicho de otra manera ¿lo que hoy conocemos por escuela es básicamente la misma que nació con la ciudad?, y, 'hoy habitamos las mismas ciudades? Responder estas preguntas nos debe servir para esclarecer otra más íla escuela de hoy es pertinente para la ciudad de hoy?

Aquí no pretendemos tomar una posición en torno al debate sobre la eventual desaparición de la escuela (por ser un problema que trasciende nuestras voluntades), lo que nos interesa es mostrar su condición mutante y su compleja relación con las condiciones que le dieron existencia. Las conclusiones podrán servir o no para avanzar en la polémica, pero en todo caso debe serle útil a todos aquellos que desean ir más allá de lo que el orden social requiere.

\section{LOS NUEVOS ESCENARIOS URBANOS: LA CIUDAD QUE NOS SORPRENDIÓ}

Bogotá y Medellín, como casi todas las grandes ciudades latinoamericanas son expresión de dos fenómenos relativamente recientes: los desplazamientos masivos de la población y la industrialización ${ }^{3}$.
A partir de la década del 30 los índices de crecimiento económico y de aumento de la población, se dispararon en relación con el promedio de las décadas anteriores. No quisiéramos ahondar por ahora en las razones sociológicas o económicas que explican este hecho, simplemente constatamos, a través de una serie de datos que realmente estaba emergiendo algo novedoso.

La llegada del automóvil, de la radio, del cine, y más tarde de la televisión, fueron acontecimientos que transformaron profundamente los hábitos y las costumbres de los habitantes urbanos. El automóvil, por ejemplo iría a determinar la forma como se ordenaría el espacio en las ciudades. La construcción de avenidas y la regulación del tránsito, serán dos asuntos que van a pasar al primer lugar dentro de las prioridades de la planificación y de la inversión urbana.

La radio, por su parte revolucionaría las prácticas de la comunicación, centradas hasta entonces en la prensa escrita; pero además se convertiría en una forma de recreación y de uso del tiempo libre muy importante ${ }^{4}$; muy pronto se utilizó también como un instrumento educativo que afectaría las costúmbres y en general la cultura. Las más importantes emisoras (RCN, Caracol), poseían estudios y radio-teatros con capacidad

3. La tasa de crecimiento de Bogotá en el período 19511964 fue una de las más altas del mundo: $6.8 \%$, proveniente del crecimiento natural de la población y del flujo inmigratorio; seguida muy de cerca por Medellín con un promedio de $5.2 \%$.

4. En un aviso de la revista Semana, publicado en agosto 26 de 1950, se señalaba: “....cada una de las tres ediciones del radioperiódico actualidad transmitidas a las 12:30, 7 y 9:30 de la noche por Emisora Siglo XX, alcanza una sintonía que se estima por lo bajo en 100.000 oyentes". 
para más de 500 personas, localizados en Bogotá y Medellín, donde se reunían varias veces al día, a observar las presentaciones musicales y la transmisiones de las radionovelas. Estas prácticas cambiaron muchas 42 de las rutinas tradicionales, más propias de las villas y los poblados, donde el ocio se ocupaba de otras maneras.

El cine fue algo así como una obsesión desde que hizo su aparición en el escenario urbano; la asistencia a las salas era prácticamente masiva, se trataba de un espectáculo que cautivaba a todos los sectores de clase y a todas las edades en 1951, Medellín tenía 31 salas de cine, que proyectaban hasta 3 funciones diarias. En Bogotá, en 1953, había 55 salones de cine, se dieron 60.759 funciones, entraron $12^{\prime} 105.817$ espectadores, y pagaron, $\$ 13^{\prime} 265.561-$. Estos datos fueron contrastados con la crisis del teatro, considerado como el espectáculo más popular antes de la llegada

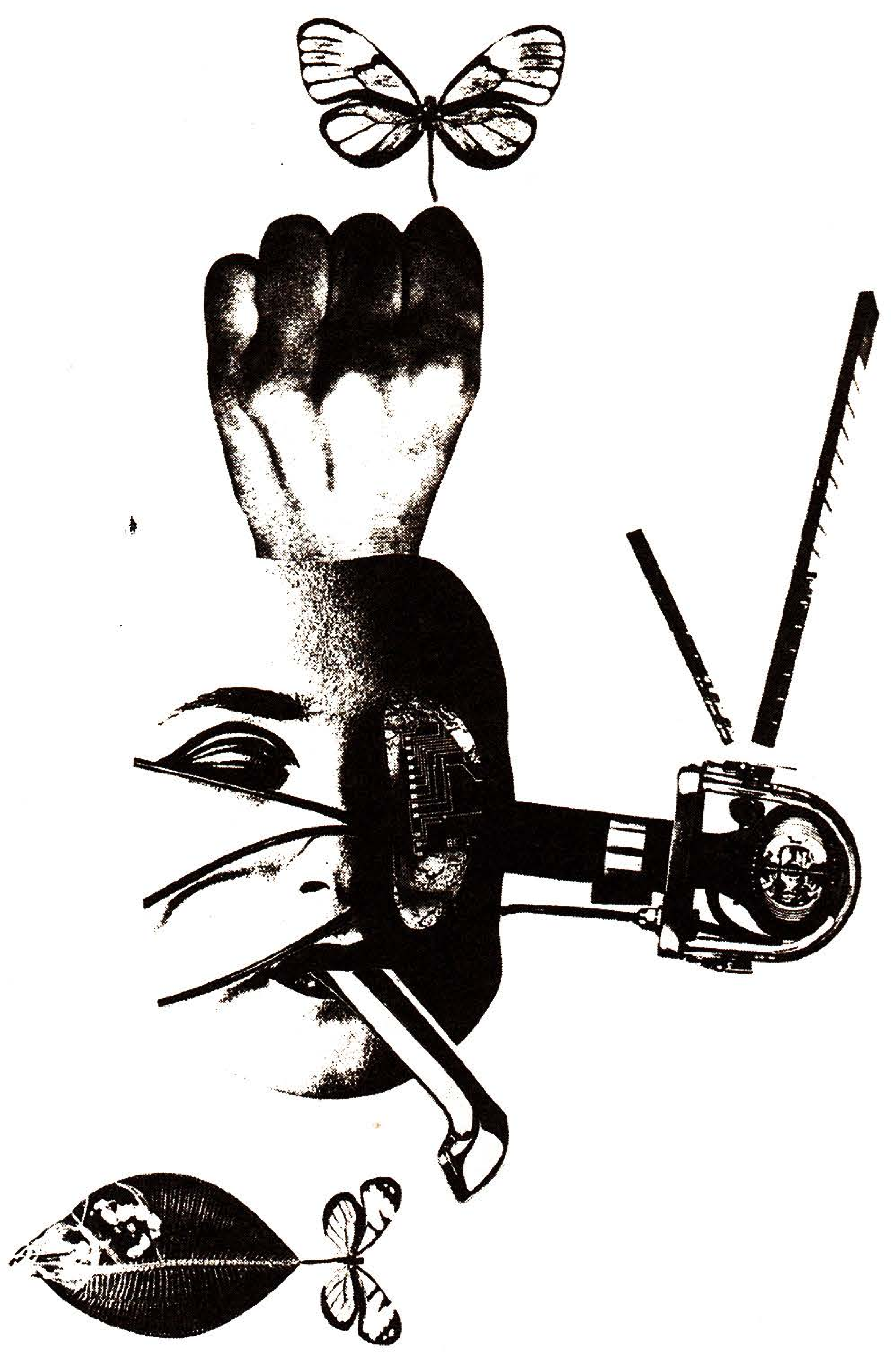

del cine: -en 1956, se dieron 370 funciones, asistieron 70.150 personas y se recaudaron $\$ 400.000$ - Desde muy temprano la industria internacional del cine supo explotar la magia que poseía la proyección de imágenes vivas y la representación de un imaginario creado y recreado de millones de habitantes urbanos del mundo entero.

Finalmente la televisión reordenó radicalmente la cotidianidad doméstica y se convertiría en el medio de comunicación de masas más importante. (El análisis de su impacto y su trascendencia en la transformación de la cultura contemporánea, merece un capítulo aparte que exploraremos en su momento).

Era como si la ciudad misma se estuviera sorprendiendo de lo que nacía a sus pies, como si estuviera asistiendo a su propia mutación y se sintiera extranjera en su propio espacio. 


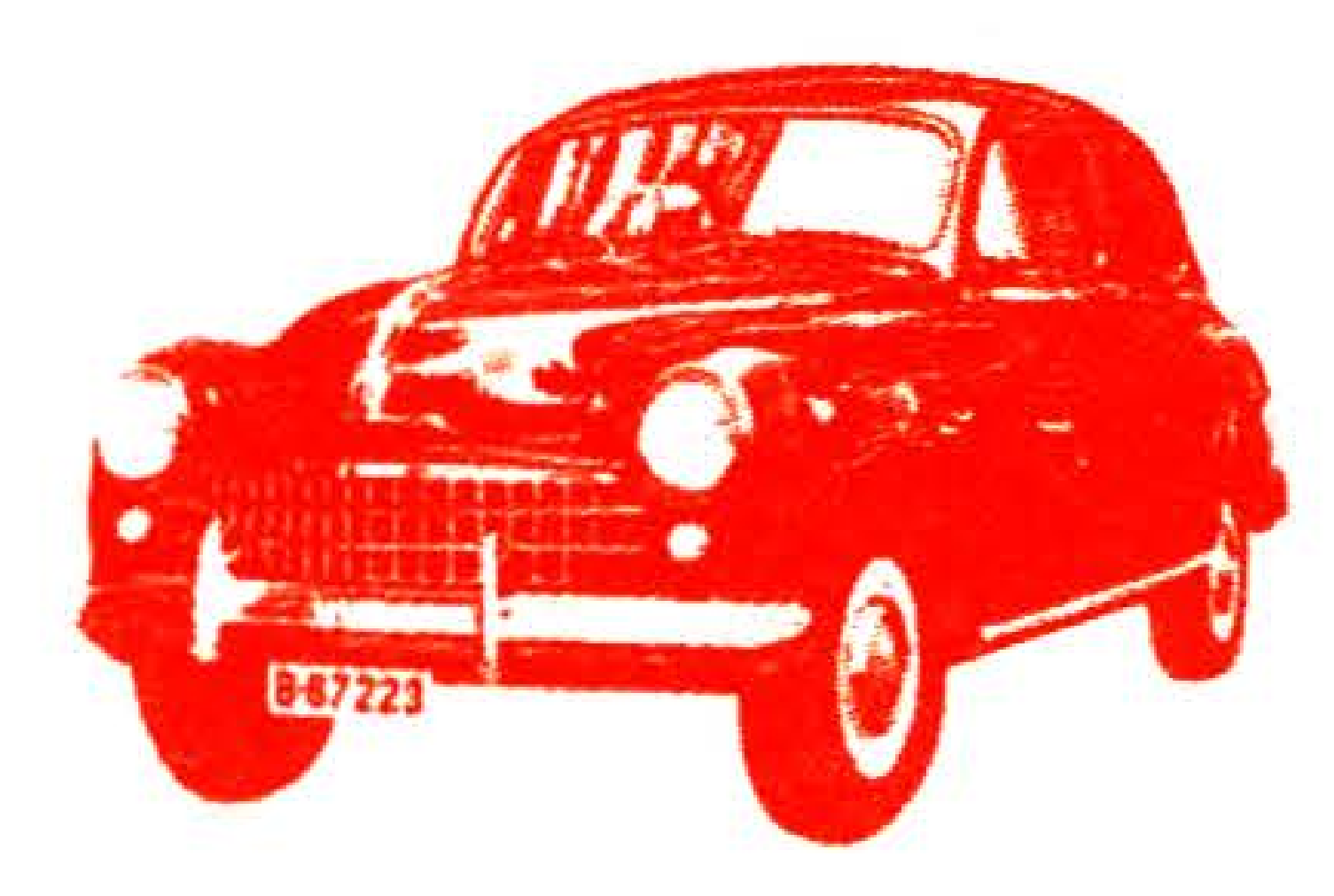

Este proceso de urbanización era visto en un comienzo con cierto entusiasmo, al punto que se deseaba... como si todo aquello fuera signo de progreso, como si se estuviera asistiendo por fin al comienzo de una nueva era que nos introducía a un mundo de bienestar, ciencia, verdad y perfeccionamiento.

El fenómeno del crecimiento urbano estuvo asociado entonces al aumento de la población urbana y al desarrollo económico. Ahora bien este proceso trajo nuevos problemas, como el de la delincuencia, la mendicidad, el hacinamiento, el aumento de la morbilidad, la accidentalidad, la pobreza. Junto al entusiasmo y el optimismo generado por el crecimiento, comenzaron a escucharse voces de alarma o de precaución. Una expresión de las advertencias que se comenzaron a hacer la encontramos a propósito del agua, en la revista Semana de 1950:

"El final del año encontró a muchos bogotanos discutiendo entusiasmados la noticia publicada por el diario El Liberal la semana pasada, sobre que la población de la capital había llegado a 1.000.000 de habitantes. Aparte de las gentes tradicionalistas que no se conforman con que la ciudad haya perdido los encantos de antaño, los demás no dejaron de expresar, en público, cierto orgullo. El entusiasmo, sin embargo, se enfrió

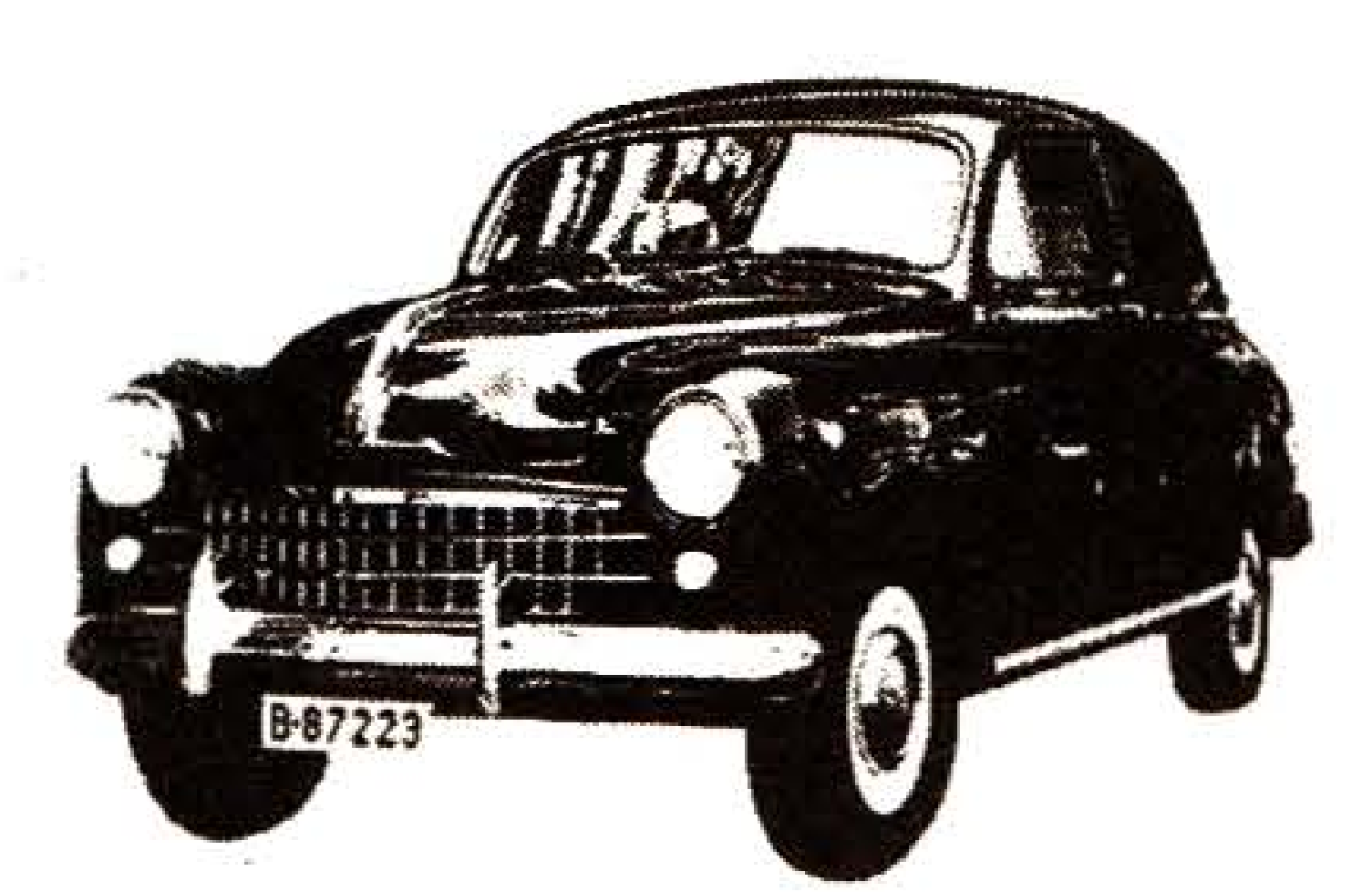

algunos días después, cuando se supo que la represa de "La Regadera", principal fuente de abastecimiento, para las necesidades de ese posible millón de habitantes, estaba bajando de nivel, a tiempo que apenas comenzaba la época de verano o sequía"5.

Hasta mediados de la década del cincuenta, podríamos decir que predominó el entusiasmo, luego vendría el escepticismo y la preocupación por algo que tendía a volverse inmanejable. A pesar de todo, el crecimiento no se detuvo, el capitalismo necesitaba expandirse y la violencia no cesó.

Carlos Sanz de Santamaría, alcalde de Bogotá durante el períod@ 1942-1944, en una entrevista realizada en 1987, recuerda:

“Otro de los problemas que provocó el desplazamiento de gentes por culpa de la violencia, fue el de los gamines. Vagaban por las calles y pedían limosna. Con mi mujer tuvimos que recibir centenares de menores, sobre todo del Tolima. Ella organizó varias casas para darles un alojamiento provisional. Fortalecimos también dos o tres instituciones, que no eran reformatorios, por

5. En: Revista Semana, Volumen VIII, No. 168, enero 7 de 1950, Bogotá, pág. 15. 


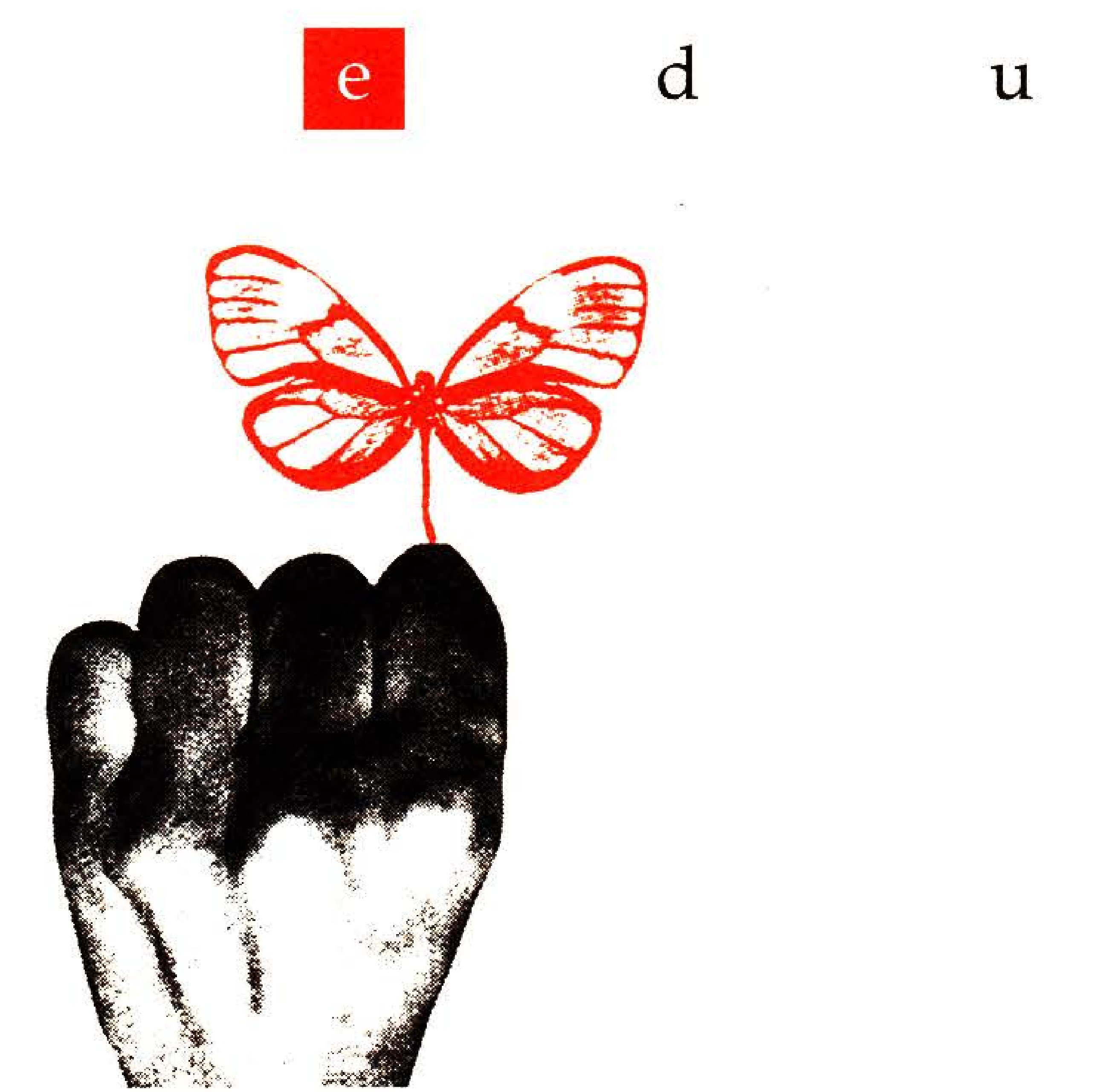

cuanto los niños no habían cometido ningún delito, sino una especie de hogares de paso, algunos ubicados en Fusagasugá y otros en el casco urbano de la ciudad. Pero imagine usted el problema: doscientos, trescientos niños diarios, provocaban un conflicto imposible de atender, era una solución sumamente compleja. De otra parte la miseria era inmanejable. En Sibaté los hospicios estaban llenos hasta el tope, lo mismo que las entidades de diferente orden, que actuaba cada cual por su lado, sin obedecer a un proyecto global. No había seguro social y muchas veces trabajadores y empleados carecían de servicio médico. Los grandes hospitales, San Juan de Dios, La Hortúa y La Misericordia, pertenecían al departamento. En una palabra atravesábamos una época dura, difícil, sometida a toda suerte de adversidades"

En 1950 las estadísticas arrojaban los siguientes datos para Bogotá:

“a) 453 vehículos, entre automóviles, bicicletas y vehículos de tracción animal fueron robados en la capital durante 1949. b) Los agentes de vigilancia condujeron a los diversos juzgados permanentes de policía 7.137 casos de robos, homicidios, heridas y otros atentados contra la vida o la propiedad. c) 967 personas, principal- mente niños, mujeres y ancianos, desaparecieron de sus hogares"7.

Con respecto a la educación formal, una monografía de Bogotá publicada en 1959 decía lo siguiente:

"La enseñanza elemental y pública constituye hoy para el Distrito Especial un problema muy serio que tiene que resolver cuanto antes. Bogotá tiene cien mil niños en estado escolar; treinta mil reciben enseñanza en establecimientos particulares; otros treinta mil la reciben en establecimientos oficiales, y cuarenta mil niños se quedan sin instrucción. Hacen falta edificios para escuelas; este es el problema más urgente para resolver"s.

Para el caso de Medellín, encontramos en el censo que hiciera en 1961 la Arquidiócesis de la ciudad, lo siguiente:

"Medellín 565.000 habitantes que, juntándolos con los de Bello, Envigado e Itagüí, formaban una sola ciudad de $775.010 \ldots$ l) Cerca de 26.000 analfabetos totales; 2) 17.000 hombres de 18 a 60 años que se embriagan frecuentemente; 3 ) 13.000 madres solteras; 4) 1.870 tugurios con cerca de 6.000 habitantes, sin contar 93 pasajes, cada uno de los cuales alberga de 5 a 14 piezas con cocina y lavaderos comunes. A los datos anteriores es preciso agregar otros, que nunca se

6. Juan Mosca, Bogotá ayer, hoy y mañana, Bogotá, Villegas editores, 1987, pág. 102.

7. En Revista Semana, Volumen VIII, No. 172, Febrero 4 de 1950, Bogotá, pág. 16.

8. Rafael H. Florencio, Bogotá Distrito Especial, Bogotá, Librería Stella, Tercera edición, 1959, pág. 104. 
publicaron, por disposición del Sr. Arzobispo, como número de rameras, prostíbulos, uniones adulterinas, adultos que no van a misa dominical, cantinas, estaderos, garitos de juego... A pesar de los adelantos de todo género, Medellín es una ciudad que tiene grandes y pavorosos problemas. La prostitución y el vicio, como sucede en grandes urbes, se entró de rondón al propio centro... La rapiña pública, el atraco, la prostitución, el contrabando, la miseria y el vicio le muerden no ya los talones sino el propio corazón, a la orgullosa ciudad de Medellín y los cinturones de tugurios, se encuentran también en ese corazón. A pesar de tantos esfuerzos, cada año se quedan miles de niños sin escuela primaria... Esta sociedad tecnológica, fruto de la expansión industrial que pasó a la máquina, al trabajo mecanizado, eléctrico y electrónico, es muy complejo en Medellín. Las desigualdades crecen; la falta de moral, la multiplicación de la llamada "industria del crimen", ha creado una urdimbre atroz y secreta..."

La ciudad se convirtió en aquel escenario en el que se concentraron los principales problema que habrían de caracterizar el modelo de desarrollo propio del Tercer Mundo.

Esta serie de acontecimientos que transformaron radicalmente la vida de los bogotanos y de los Paisas, se sucedieron de alguna manera intem- pestivamente, es decir sin que hubiera habido una clara intencionalidad de parte de algún dirigente o alguna fuerza económica o política. Sin embargo quizás la misma sorpresa fue la que contribuyó a consolidar la idea de que la ciudad podía y debía ser imaginada. La lógica de la planeación, que tiene que ver con una serie de cambios en el orden de lo social en su conjunto, se convirtió casi en una obsesión, de tal manera que hablar de ciudad era equiparable a planificación. El propósito de los gobiernos municipales fue, desde finales de la década del 40 administrar la planeación. De alguna manera, el pesimismo causado por los graves problemas que trajo el modelo de urbanización, no podía acabar con el sueño de ser grandes. Había que proyectar los planes de vivienda, las vías, el acueducto, la luz, en fin, los servicios y una serie de necesidades que eran nuevas. Para el caso de Bogotá, podemos ver el impacto de esta tendencia en el Plan Piloto que se contrató hacia 1950:

"El Plan Piloto fue entregado la semana pasada por los encargados de elaborarlo: Charles Edouard Jeanneret (Le Corbusier) y sus asociados

9. Humberto Bronx, Estudios Históricos y Crónicas de Medellín, Medellín, Colección Academia Antioqueña de Historia, 1978, pág. 227-228.

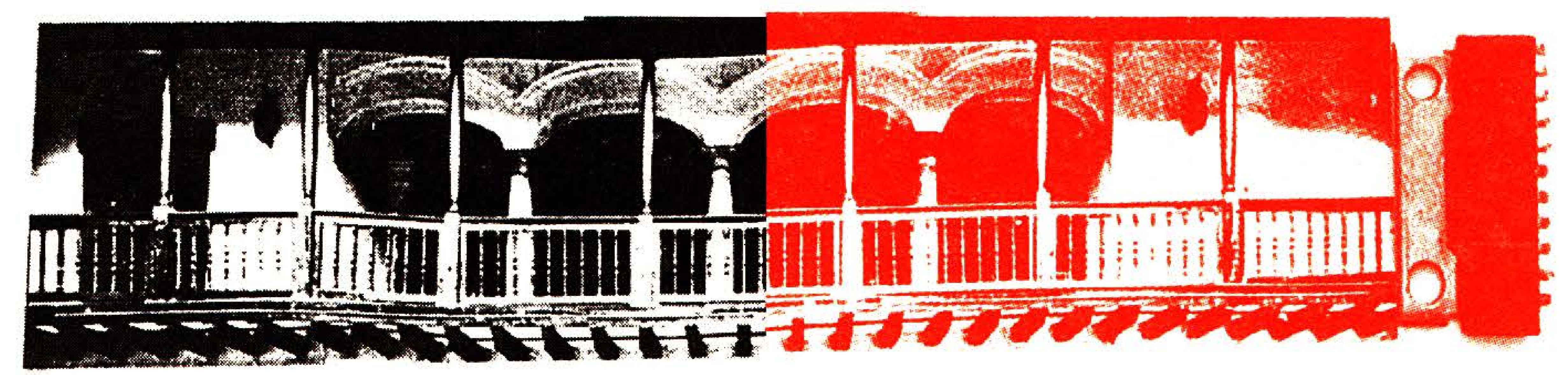


José Luis Sert (español) y Paul L. Wiener (estadinense)... El Plan Piloto consiste en lo siguiente: es la proyección general de la ciudad del futuro... que conforme a la arquitectura funcional debe reunir cuatro funciones básicas: 1. edificios de habitación, 2. edificios de trabajo (oficinas, talleres, fábricas), 3. ambiente para el desarrollo del 46 cuerpo y el espíritu (parques, bibliotecas, escuelas, gimnasios, estadios, templos, etc.), 4. vías de circulación (avenidas-arterias, carreras y calles ordinarias, parqueaderos, etc.). Todo conforme al principio de que el desarrollo de las ciudades debe obedecer a las necesidades del hombre y no a la inversa, que el hombre obedezca a las limitaciones de la ciudad"10.

La administración de estos problemas fue lo que configuró la estrategia de la planeación que le daría un nuevo perfil a nuestras ciudades.

Nuevos problemas jalonaron nuevos discursos, como el de la planeación, pero también surgie-

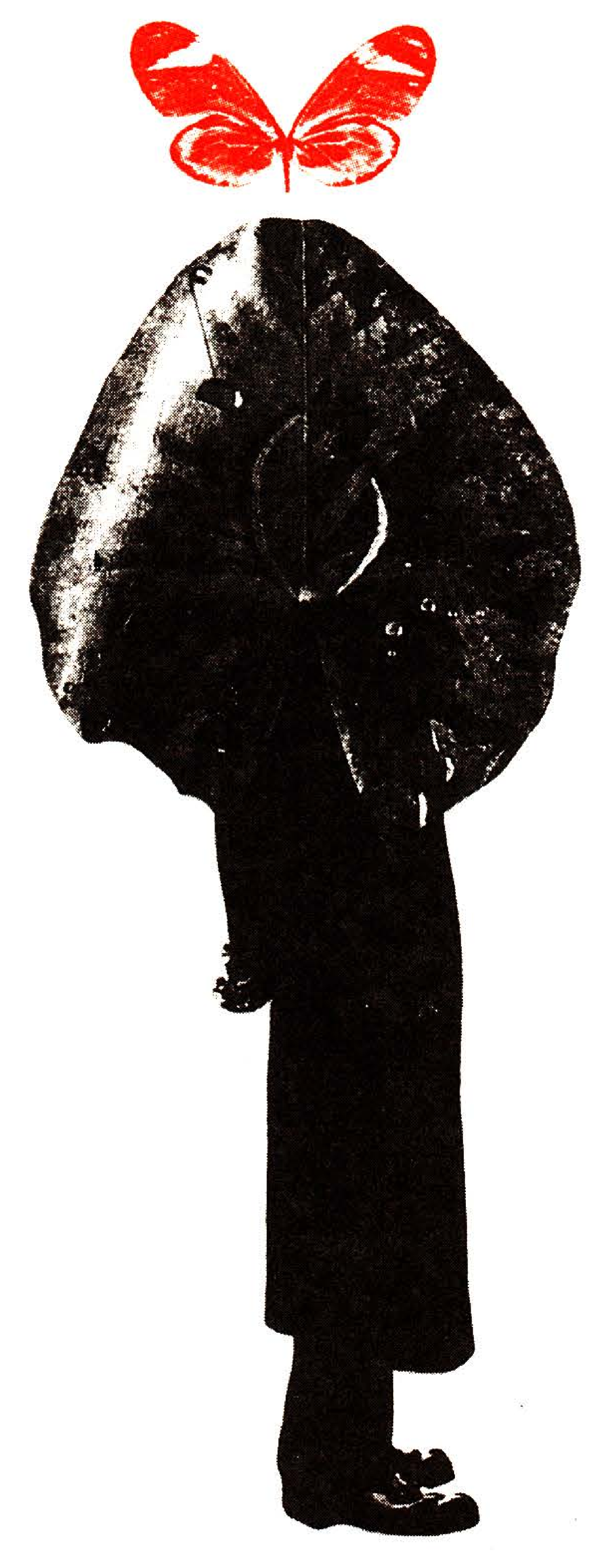

ron otros dispositivos de control social, que dieron cuenta de las estrategias a través de las cuales se fue resolviendo el problema del gobierno de la población en estos nuevos contextos urbanos.

En un artículo de la revista de las Fuerzas de Policía de Colombia, de 1955, la estrategia se plantea de la siguiente manera:

"...constituye un deber preliminar rendirle férvido tributo (a la obra de servicio social) por su intervención afortunada en los complejos menesteres de las necesidades sociales; y presentar su obra múltiple, en ciudades y campos; en instituciones y en conglomerados disímiles, con grandes y pequeños; en familias y en casos aislados; en industrias; ante enfermedades y ante enfermos; en orientación; en prevención de la delincuencia; en educación, ante calamidades colectivas; en cultura popular; en asistencia pública y social..."
10. En Revista Semana, Vol. IX, No. 204, septiembre 16 de 1950, Bogotá, p. 9.

11. Miguel Bernal Medina, "Tribunal de Menores y Servicio Social" en Revista Fuerzas de Policía de Colombia, nov-dic, 1955, Nos. 41 y 42, Bogotá. 


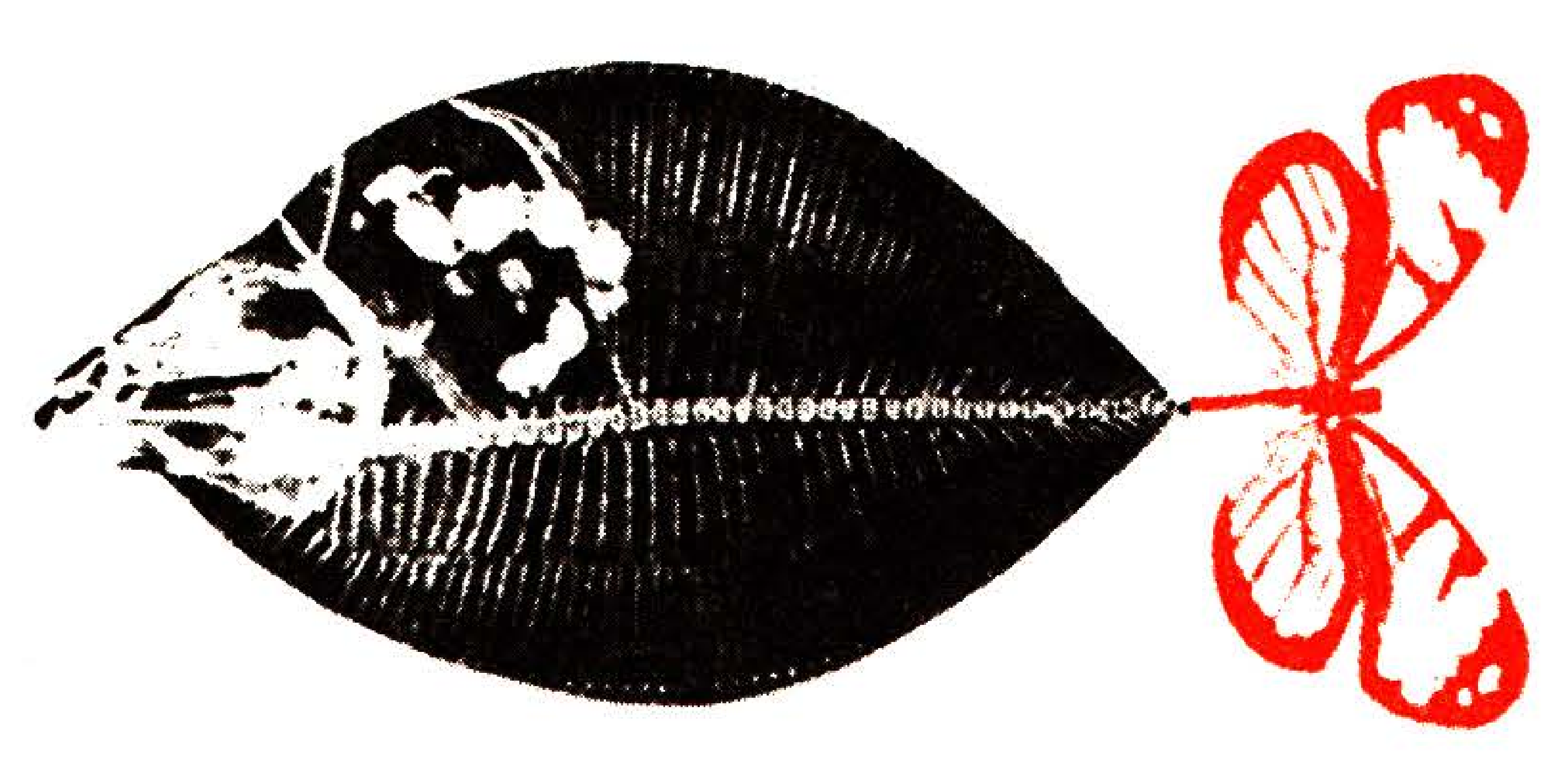

Todo este conjunto de acciones reorientaron la práctica política, el ejercicio del poder y las técnicas de control de la población. En el contexto de este giro histórico es que podemos entender el cambio que sufrieron las políticas educativas y el nuevo lugar que ocuparía la escuela. La ciudad se había convertido por sí misma en un escenario educativo, de tal manera que el gobierno de la población pasaría por el control de la ciudad antes que por el control del alma y del cuerpo, vieja función de la escuela.

\section{UNA NUEVA EDUCACIÓN PARA}

\section{UNA NUEVA CIUDAD}

En 1953 aparecían relacionadas dentro del presupuesto del Departamento de Instrucción Pública (en Bogotá), además de las escuelas primarias: el Colegio Mayor Municipal, la Universidad Municipal Popular, la Sección de Escuelas Integrales y Capacitación Obrera, el Instituto Complementario de Varones, el Instituto Complementario de Varones No. 2, el Instituto $\mathrm{Mu}$ nicipal de Comercio, el Instituto Complementario del Sur, el Instituto Complementario Femenino, el Instituto de Cultivos y Viveros del Corregimiento de Nazareth, Estación de Cuarentena y Observatorio Infantil. Para ilustrar el tipo de educación que se daba en estos establecimien- tos, veamos algunos de los profesores que tenía la Escuela de Capacitación Integral Obrera para Varones: 1 Asistente social, 1 Jefe de disciplina 4 Jefes de grupo, 4 profesores de grupo, 2 profesores de canto y música, 1 Experto agrícola, 1 Instructor de agricultura, I Jefe de taller de carpintería, 1 Jefe de taller de mecánica, 2 Enfermeros, 2 Peluqueros. ${ }^{12}$

Y en 1951, en Medellín, existían: La Escuela Normal de Institutores, la Escuela Nacional de Minas, la Escuela de Medicina y Jurisprudencia, el Colegio Odontológico, la Escuela Pascual Bravo, la Escuela Politécnica Militar, la Escuela de Sordomudos, la Escuela Modelo ("Expresamente establecida para preparar el magisterio rural. Allí se da enseñanza gratuita a señoritas pobres pero honradas; y además: instrucción, asilo y alimentación. Algunas de las alumnas adquieren allí también conocimientos muy satisfactorios de telegrafía, dactilografía, corte, costura, sombrerería y de otras obras manuales"), el Central Femenino, la Universidad Obrera, la Universidad Femenina o Colegio Mayor de Antioquia, el Instituto Psico-Pedagógico (para niños de difícil educación. Se reciben enfermos mentales.), la Colonia del Perpetuo Socorro (para albergar niños escolares débiles, por un período de 90 días), la Escuela-Hogar (para prevención de niñas menores desorganizadas, abandonadas e inclinadas al delito. También conocida como Instituto Médico Pedagógico de Anormales). ${ }^{13}$

12. Decreto Numero 890 , por el cual se expide el Presupuesto de Rentas y Gastos para la vigencia fiscal de 1954. Diario Oficial, diciembre 28 de 1953, Bogotá, p. 109.

13. Daniel Restrepo, Monografía eclesiástica y civil de Medellín, Medellín, Ed. Bedout, 1951, pp. 132 a 145. 
Esta relación de instituciones nos da cuenta de la necesidad de atender a aquellos sujetos recientemente configurados y constituidos por la ciudad. Cuando un campesino llegaba a la ciudad, pasaba a convertirse en un potencial obrero. La vieja matrona campesina de alguna provincia antioqueña, capaz de congregar a su alrededor hasta tres generaciones y de influir sobre ellas con sus preceptos, sus mandatos y sobre todo su ejemplo, se vería amenazada cuando alguno de sus vástagos, por alguna razón viajara al Medellín de los años cuarenta o cincuenta, y aún peor si fuera de los sesenta. A su regreso, seguramente tendría que reconocer su impotencia. En la ciudad quedaría atrapado por alguna de estas instituciones que le definirían su nueva condición: mendigo, obrero, profesional, técnico...

En ese sentido la ciudad estaba demostrando su inmenso potencial educador. En realidad ella creó nuevos sujetos, distintos, muy distintos, a los que la escuela había formado durante más de cien años. La industrialización, las nuevas tecnologías de la comunicación y las complejas relaciones sociales que se tejieron en estas redes urbanas, fueron
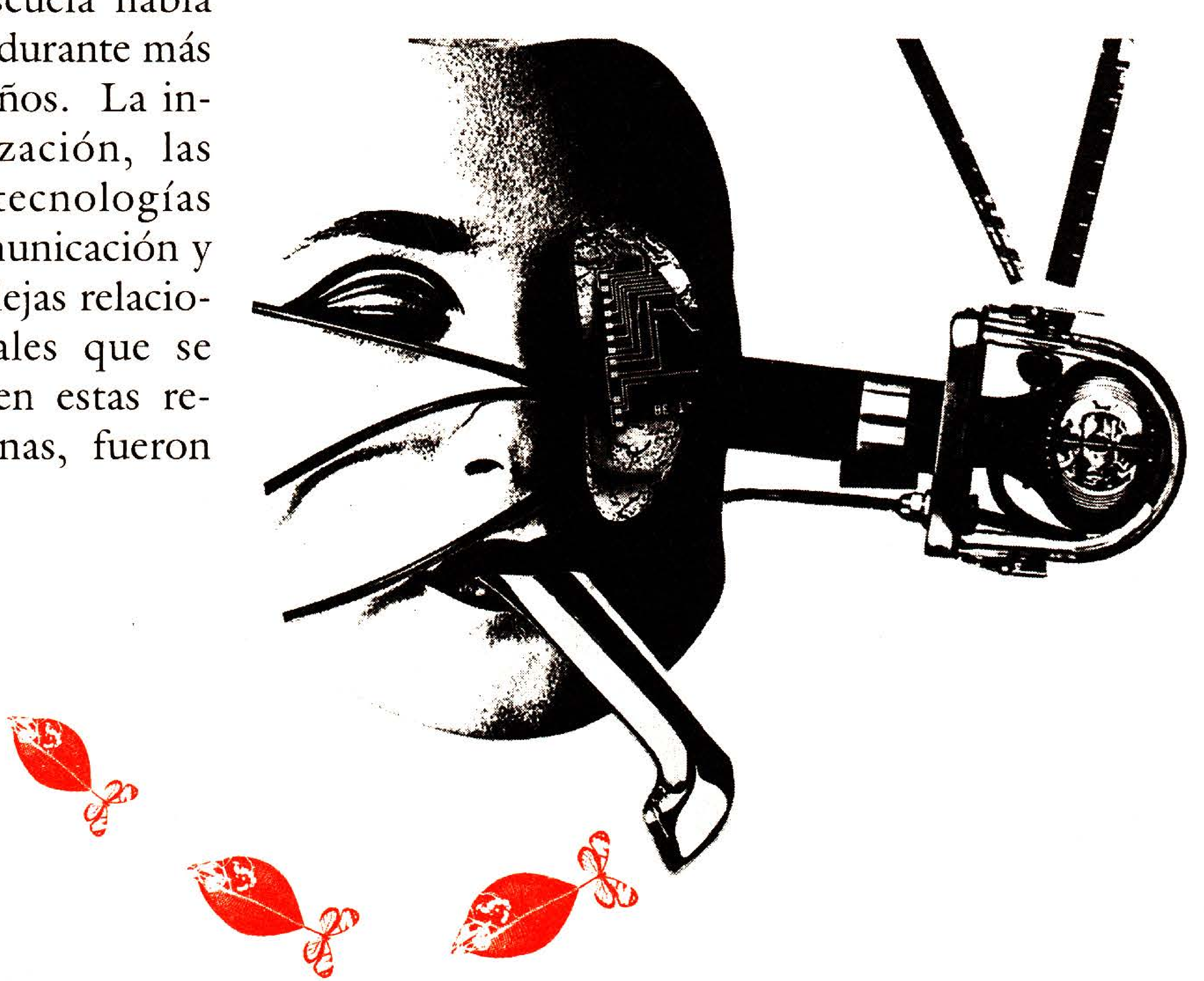

configurando nuevos sujetos; un nuevo modo de ser hombre y sobre todo un nuevo modo de ser mujer ${ }^{14}$ fue emergiendo, en medio de las prácticas escolares tradicionales.

Además de este nuevo tipo de instituciones, la ciudad se preocupó también por el tiempo libre de sus habitantes. De esta manera proliferaron los discursos, los planes y los proyectos relacionados con las actividades de recreación que supuestamente requería la población. Asunto clave para el tema de la gobernabilidad. Los parques, las presentaciones musicales y de danzas, los teatros, los deportes de masas, etc, fueron el objeto principal de muchas de las administraciones de este período. Había que garantizar el progreso moral de la población, junto con el progreso material. Como ejemplo de esta preocupación, veamos algunas de las conclusiones a las que lle-

4. El nuevo rol que las mujeres comenzaron a jugar en la familia y en la sociedad quizás no provenga tanto de una conciencia feminista liberadora que despertó por fin después de milenios de injusta dominación, sino de la redistribución de funciones y por lo tanto de la mutación de las consciencias y de la "naturaleza" de los nuevos sujetos sociales. 
garon en el Congreso Interamericano de Municipios, realizado en Montevideo en 1953:

“a) La salud física y espiritual del pueblo está en directa vinculación con la manera de administrar y organizar el tiempo libre; b) La organización racional de las horas libres fortifica física y psíquicamente, aumentando las actividades y contribuyendo así al acrecentamiento de la fuerza, a mejorar su educación y cultura y a formar y elevar la moral del ciudadano; g) Compete a la iniciativa pública la tarea de asegurar legalmente, suficiente tiempo libre así como planear la organización de este tiempo libre; habilitar en las ciudades los espacios, los locales y las instalaciones para ese objeto, como también facilitar los elementos para su programación y su cumplimiento; h) Toda recreación infantil o de adultos debe desarrollarse bajo un vigilante y capacitado control física, social y pedagógico. ${ }^{15}$

Educar en la ciudad y a la ciudadanía, he ahí el nuevo problema. Ha quedado atrás el viejo supuesto de que solamente es educable la infancia. Antaño, la escuela se justificaba y se colocaba en el centro de la estrategia del gobierno de la población, porque se suponía que de la labor que se hiciera allí, dependía el futuro de la población adulta. Aún se creía que... "árbol que crece torcido, nunca jamás se endereza”.

Ahora bien, este viejo dicho aún tiene sus seguidores. De hecho, la emergencia de la ciudad moderna, configurada como un gran escenario educativo, significó desde el comienzo una franca oposición, una resistencia activa motivada desde la escuela.

Aparecieron muy pronto los comités de censura del cine y luego, a su turno, de la televisión;

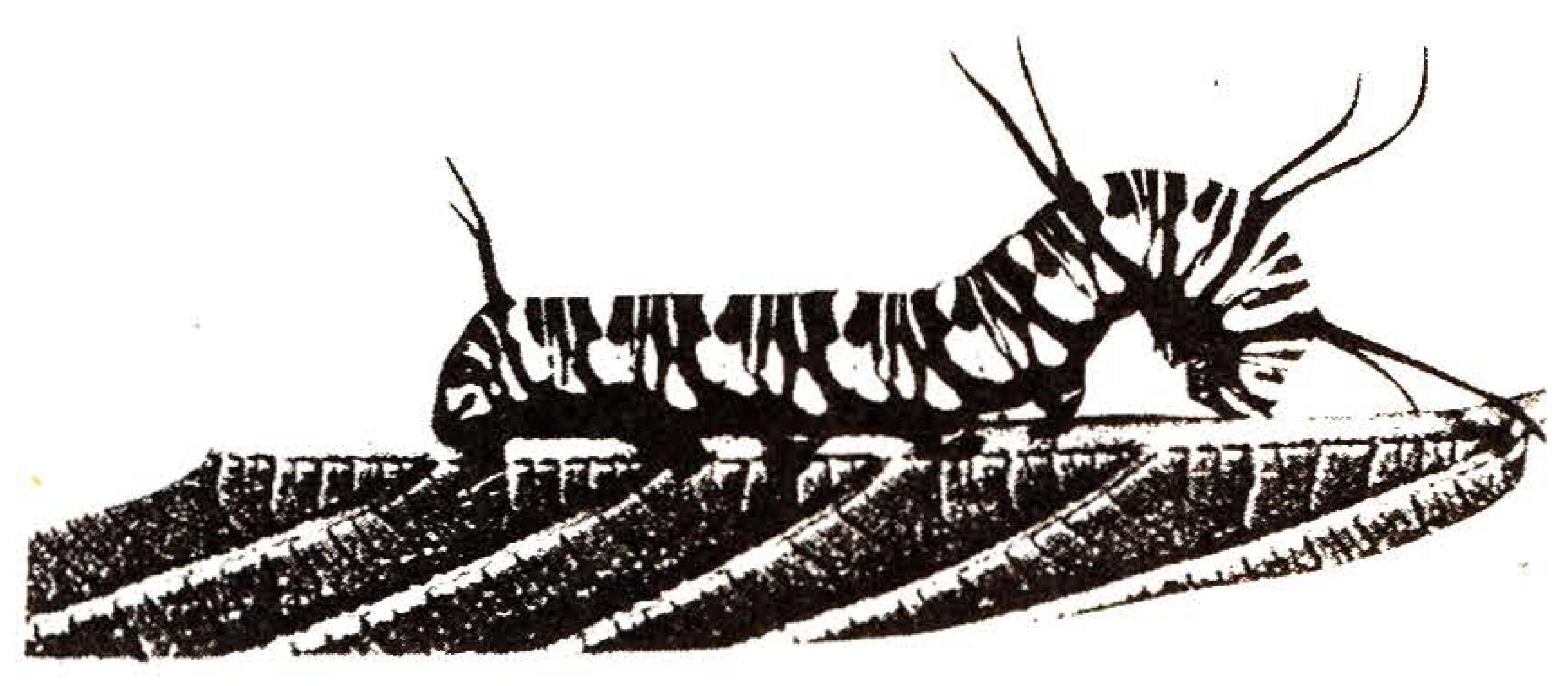

también se censuró la radiodifusión y por supuesto los espectáculos públicos.

Para el caso del cine, la reacción fue violenta, escuchemos algunos de los argumentos que hicieron parte de la intensa confrontación social que se generó en torno al problema de la educación:

"El cine es la distracción más popular y la más peligrosa, porque presenta ante sus espectadores las pasiones humanas desbordadas hacia todas las actividades, con frecuencia hacia las más bajas y desvergonzadas. Si nos damos cuenta de que las inclinaciones se forman por la repetición de actos y de que los ejemplos tienen una influencia definitiva æobre éstos, se comprende esa atracción creciente por las películas excitantes y malas, y se comprende también ese cúmulo de picardías y de crímenes que se ven por todas partes. El cine relaja la sensibilidad social y con ella disminuye la rectitud y la hombría. El cine es una escuela donde se aprenden los sistemas para engañar: los trucos de los ladrones, las emboscadas de los apaches; donde se estimulan el odio,

15. Informe del observador Colombiano en el Congreso Interamericano de Municipios realizado en Montevideo, Diario Oficial, marzo de 1953, Bogotá, pp. 272-273. 
la venganza, la embriaguez, el juego, la infidelidad, la pereza, el suicidio, el libertinaje..."16

Las razones que se aducían siempre tenían que ver con la moral. El principio moral era fundamental en tanto que se reconocía el influjo que alcanzaban a tener sobre las personas; en últimas se trataba del reconocimiento de la función educativa de estos medios. Toda vez que la escuela debía seguir siendo la institución educadora por excelencia, se le reclamaba a estos nuevos mecanismos el poder dañar la acción purificadora que realizaba la escuela. La escuela entonces debía ser protegida. Con respecto a los salones de baile, por ejemplo, se advertía que no podían quedar cerca de los templos y las escuelas, tal como lo advirtió un decreto del Alcalde de Bogotá en 1952:

"Artículo 1. Los salones de baile que existen o en lo sucesivo se establecieren en la ciudad, se clasificarán en dos clases: a) Salones sociales de baile o clubes nocturnos, y b) Salones públicos de baile o coreográficos. Artículo 2. Entiéndese por salones sociales de baile o clubes nocturnos aquellos establecimientos que independientemente o anexos a los hoteles, además de prestar servicios de comedores y bar, mantienen orquestas, disponen de pista de baile para uso de los clientes y no tienen contratadas en ninguna forma c

a

C

i

ó

$\mathrm{n}$

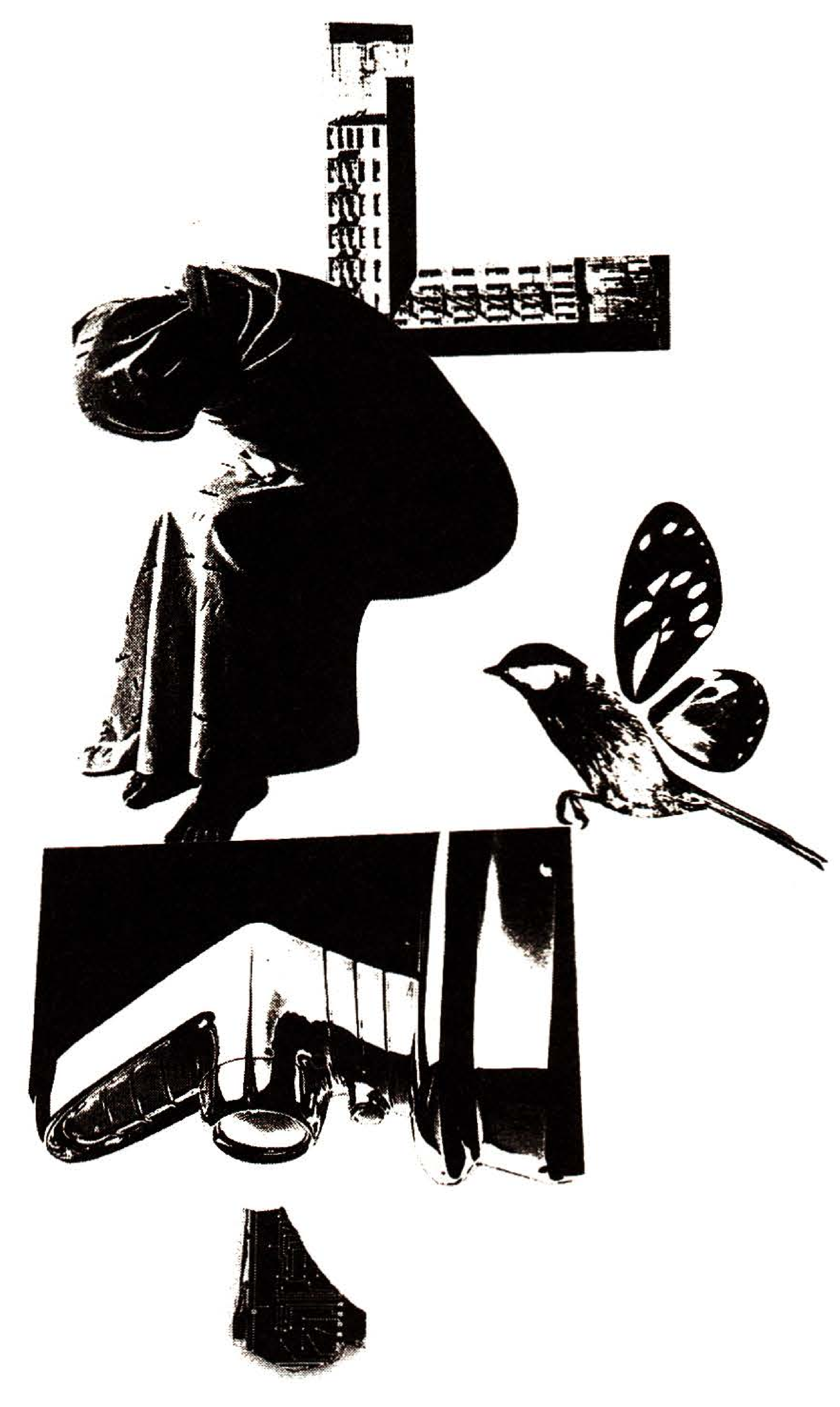

empleadas que desempeñen el oficio de danzarinas o compartan las mesas con los clientes. Artículo 3. Entiéndese por salones públicos de baile o coreográficos aquellos establecimientos en los cuales se contraten o admiten danzarinas a sueldo, porcentaje, o cualquier otra forma semejante. Artículo 7. Ninguno de estos establecimientos podrá funcionar a menos de dos cuadras de

16. Florencio, ob cit. pp. 108-109. 
los templos, iglesias, escuelas, y, en general de establecimientos de educación"17.

Se trata de esa idea de pulcritud y de territorio neutral, no contaminado, que debía tener la escuela.

La ciudad encontraba en ella el bastión de la moral. Quizás era el último resquicio en el que se podrían conservar los valores que de por sí la ciudad había trastocado. ¿Fue este el momento en el que la escuela se colocó al margen de la ciudad y de sus procesos complejos de modernización?

\section{PRIMERAS APROXIMACIONES TEÓRICAS}

Quedan todavía muchos aspectos por revisar. La mayoría de las referencias están tomadas de la década del cincuenta, lo cual nos deja pendiente por explorar el resto del período, para mirar rupturas y continuidades. El análisis comparado entre Bogotá y Medellín también nos debe arrojar datos interesantes para ver los matices culturales y económicos que marcaron las diferencias y para ver aquellas coincidencias que nos po- drían acercar a hipótesis generales. Ante todo tenemos claro que la ciudad es un espacio pluricultural, diverso, múltiple y complejo, de manera que siempre será importante mirar caso por caso, para encontrar en cada uno la riqueza de su multiplicidad.

Lo que estamos encontrando es la forma como la ciudad se ha pedagogizado, pero no en el sentido neutral al que se alude cuando se habla de ciudad educadora (en el sentido positlvo del término), sino en tanto que configura subjetividades, en tanto que crea sujetos - sujetados- hábiles para desempeñarse funcionalmente (urbanizadamente) en este escenario.

Ahora bien en estos escenarios pedagogizados se cruzan múltiples tradiciones produciendo un mestizaje cultural, también muy propio de las ciudades. Hay allí unas relaciones que producen

17. Decreto No. 674 por el cual se reglamenta el funcionamiento de los salones públicos de baile en la ciudad, Diario Oficial, noviembre 20 de 1952, Bogotá, p. 289. 
sujetos a través de un proceso permanente de negociación de sentidos.

¿Cuáles son esos escenarios?, ¿son todos?, ¿es toda la ciudad la que se pedagogiza?, o hay algunos en particular. En principio, aunque creemos que es toda la ciudad la que constituye subjetividades, pretendemos diferenciar algunos que consideramos pedagogizados en un sentido más explícito. Por eso nuestro interés se ha centrado en los medios de comunicación, en las actividades recreativas programadas para manipular el ocio, y en las instituciones educativas diferentes a la escuela básica. Nuestro interés es llegar a establecer de una manera más o menos exhaustiva, la forma como acontece allí lo educativo, en qué sentido y de qué manera educan esos espacios, cada uno de ellos.

Paralelamente miraremos lo que le fue pasando a la escuela. Con la llegada de todos estos nuevos escenarios educativos la escuela tuvo que haber sufrido algún cambio o, por lo menos, tuvo que haber reaccionado de alguna manera. Nos interesa conocer la forma como se fue dando este proceso. Sabemos que a partir de la década del treinta las políticas educativas señalaron de una manera la necesidad de formar ciudadanos productivos; más adelante en la década del cincuenta, se generalizó el discurso sobre el desarrollo y allí quedó inscrita la función educativa. En la década del sesenta, se amplió significativamente la cobertura escolar y comenzó el proceso de tecnologización de la enseñanza. La pregunta sería: ¿qué relación tuvieron estos cambios con el fenómeno de urbanización?, de esta manera podremos comenzar a entender cuál fue el impacto que la ciudad causó sobre la escuela.

Pero de otra parte también sabemos que la estructura misma de la escuela, su manera tradicional de distribuir el espacio y el tiempo, sus relaciones jerárquicas, la función del maestro, en fin, su forma misma, no cambió; aun en ella se reproducen prácticas que llevan más de cien años, aún es fácil reconocer rutinas y tradiciones muy antiguas. ¿Acaso los elevados muros que la rodean hoy en día fueron construidos para protegerla de alguna amenaza?, ¿es ese encerramiento el que la ha permitido conservar sus rituales tradicionales?, ‘̇la ciudad, los jóvenes y la sociedad de hoy toleran eso?, ¿̇o hay algún malestar, algún ruido, que le atormente...?

Esto es lo que queremos investigar. La mirada histórica nos servirá para hacerle seguimiento a ese proceso. La relación entre ciudad y escuela no la podremos entender solamente desde el deseo, o desde la especulación, es necesario conocer sus coqueteos íntimos, sus odios, sus acercamientos y sus distancias, sus amores y desamores, es necesario reconstruir la historia de su encuentro... y su desencuentro.
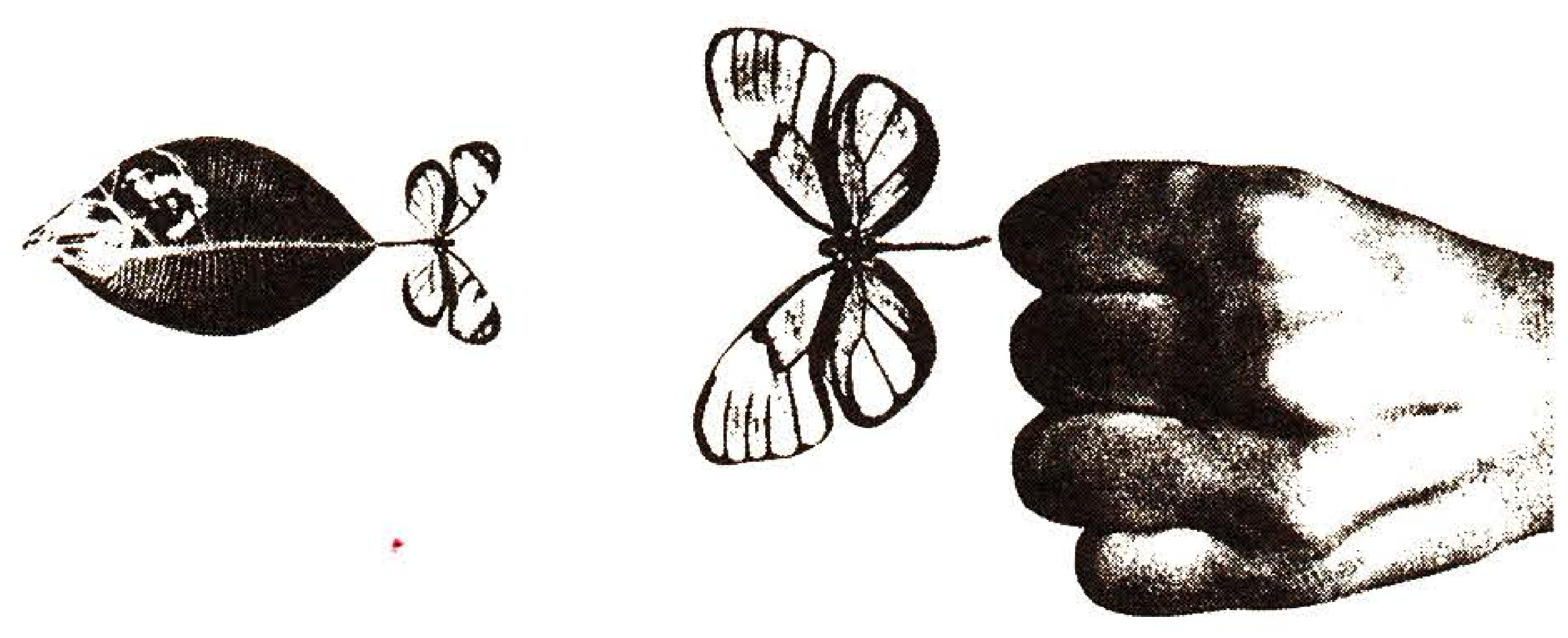